\title{
Community-based pedagogy of nursing in developing countries: An integrative review
}

\author{
Grace Nambozi ${ }^{* 1,2}$, Rozzano C. Locsin ${ }^{3,4}$ \\ ${ }^{1}$ Faculty of Arts and Sciences, The University of Hull, North Humberside, United Kingdom \\ ${ }^{2}$ Department of Nursing, Mbarara University of Science and Technology, Uganda \\ ${ }^{3}$ Institute of Biomedical Sciences, Tokushima University Graduate School, Tokushima, Japan \\ ${ }^{4}$ Florida Atlantic University, Florida, United States
}

Received: March 6, 2016

DOI: $10.5430 /$ jnep.v7n1p51
Accepted: March 31, 2016

Online Published: August 22, 2016

\begin{abstract}
Purpose: Community-based nursing education programs have been recognized for innovative pedagogies. Their influence have focused on clinical experiences of students redirected from hospital-based to community settings. However, their implementation, pedagogy, and impact on the quality of nursing education outcomes have not been clearly evaluated. The purpose of this paper was to explore the extent, nature, and quality of community-based nursing education programs in developing countries.

Methods: An integrative review was performed of published studies from January 1993 to July 2014 using the key search terms: community education, alternative clinical nursing experience, pedagogy of nursing, and clinical experience. Search was done using the Cumulative Index to Nursing and Allied Health Literature (CINAHL), Applied Social Science Index and Abstract (ASSIA, Medical Literature Analysis and Retrieved System Online (MEDLINE), British Nursing Index and Ovid SV. Two evaluation tools appraised these publications: The Critical Appraisal Skills Program (CASP UK 2014), and Preferred Reporting Items for Systematic Reviews and Meta-Analyses (PRISMA).

Results: There were 1,530 articles of which 800 were relevant citations only 38 articles met the appraisal criteria. However, five more articles were found in 2014 bringing the total to 43 articles. Five themes were revealed, the nature and purpose of community-based nursing education, significance of placement and learning environment, the impact of community-based nursing education, the challenges and sustainability of community- based nursing education programs, and nurse educator/facilitator role. Conclusions: The themes bared the nature, quality, and impact of community-based nursing education supportive of the pedagogical approach of modelling education for nursing and health care professionals, particularly in developing countries. The findings suggest that alternative clinical nursing education experiences such as community-based experiences are expected, providing quality educational outcomes. Implications for nursing and education policy: The nature, impact, and pedagogical innovations in community nursing education can inform educational policies and influence future nursing education programs.
\end{abstract}

Key Words: Community-based nursing education, Community-based education, Community placement, Integrative literature review, Impact, Innovations, Nursing education, Pedagogy

\section{BACKGROUND}

Community-based nursing education programs were implemented as an innovative pedagogical approach focusing on clinical education from healthcare institutions such as hos- pitals and clinics to community settings. This approach enhance students' learning by emphasizing the critical importance of health promotion, early intervention and illness prevention. Community-based education is a practi-

*Correspondence: Grace Nambozi; Email: Grace.Nambozi@hull.ac.uk; Address: Faculty of Arts and Sciences, The University of Hull, Cottingham Road, North Humberside, HU6, 7LE, United Kingdom.

Published by Sciedu Press 
cable model of educating healthcare professionals particularly in resource-limited communities ${ }^{[1]}$ in developing countries. The approach is similar to programs that emerged from 'Community-Oriented Primary Care' that originated in South Africa. ${ }^{[2]}$ These programs were typically multidisciplinary in nature, with the primary focus being the need for students to gain the competencies necessary for future professional practice, particularly in the community environments. Diekelmann ${ }^{[3]}$ has stressed that these new directions in educational programs demand new pedagogical approaches to schooling, learning, and teaching.

\section{The research problem}

As a relatively novel pedagogical approach linking community service and formalized educational programs developed in the past two decades, the impact of community-based nursing education on the quality of nursing education have not been clearly evaluated. The drive in the past designs were the promotion and enhancement of students' learning through multiple meaningful institutional connections of theory and practice in the real-life context of the community's own cultural values. ${ }^{[4]}$ However, there has been no comprehensive review on the state of knowledge about this educational approach. This establishes the significance of the review in reporting an integrative approach that critically evaluate community-based nursing education (CBNE) programs.

\section{INTRODUCTION}

The application of theoretical knowledge in assessing, planning and participating in educational processes provide a guide to solving community health problems. ${ }^{[5]}$ Various stakeholders such as the university or school of nursing, the community, the students, and their parents, including the teachers within the general educational school system altogether can empower the conduct of students' learning and influence educational outcomes. From a community-based focus, it was found that, real-life situations in communities make this educational approach powerful and meaningful. ${ }^{[6]}$

The preparation of nursing students who may or will ultimately work in community settings needs knowledgeable, imaginative and innovative nurse educators while supportive of students learning through novel pedagogical approaches within the community settings. ${ }^{[7]}$ Teachers must adapt to the curriculum in a manner that fosters collaboration and partnership with communities, and with other stakeholders. Linda et al. ${ }^{[8]}$ claimed that these partnerships can create more efficient and effective educational learning environments for students, while building links between community and nursing education in order to bring about a well-rounded approach to care.
Therefore, to derive data that can support the furtherance of the educational program, an integrative review of literature at the initiation of the community-based education movement was performed. This integrative review was guided by the following question: What is the extent, nature, and quality of educational outcomes that is expected of community-based nursing education programs?

\section{LiterATURE SEARCH STRATEGIES}

An integrative review was used to synthesize timely study methods and findings of articles published in peer- reviewed journals between 1993-2014. This approach is a specific method that summarizes past literature while giving a comprehensive idea and understanding of the topic. This involves the processes of "identification, analysis and synthesis of research findings from studies to determine current knowledge" (p.24). ${ }^{[9]}$ The 43 studies that met the criteria were appraised using two recognised tools; the Critical Appraisal Skills Program ${ }^{[10]}$ which guided the review of the qualitative studies and the Preferred Reporting Items for Systematic reviews and Meta-Analyses (PRISMA) group. ${ }^{[11]}$ Relevant themes identified informed the recommendations for future community-based nursing education concerns.

\subsection{Method of data collection}

A comprehensive search was conducted on the topic of community-based nursing education programs. The following databases were used; Cumulative Index to Nursing and Allied Health Literature (CINAHL); Applied Social Science Index and Abstract (ASSIA); Medical Literature Analysis and Retrieved System Online (MEDLINE); British Nursing Index and SAGE Journals using the following search terms: community education; alternative clinical nursing experience; and clinical experience and community education; and clinical experience relating to the topic. The literature search also used a list of synonyms, abbreviations and alternative spellings and word-conjunctions (nursing student/student nurse). Keywords were used in either singular or plural forms. Both British and American spellings were used. Truncation (with '*') was also used to identify some word variations.

Furthermore, educational databases such as Educational Resources Information Centre (ERIC) and JSTOR academic journals were also included. A manual search for references listed in every qualified article was carried out to identify articles that may have relevance to the topic. This process enabled the selection of appropriate studies ensuring that all the available information was incorporated. The inclusion criteria was based on the aims of the study. Manuscripts published from 1993 to 2014 that addressed community-based 
nursing education and published in English were selected.

Excluded articles were those whose focus of study were students' experiences with mentors.

There was a paucity of research studies on community education and training programs in resource-limited countries. As a result, anecdotal literature provided a valuable source of 'ideas' and philosophical thinking without which the research literature would not have contributed effectively to the findings informing the progress of nursing education into the 21 st century.

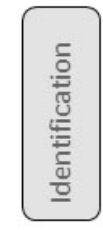

Records identified through database searching $(\mathrm{n}=1,530)$
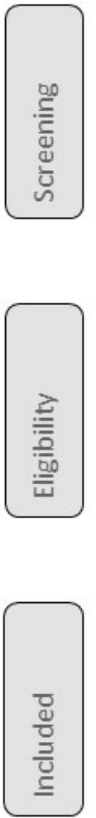

\subsection{Results of the study}

The literature search yielded 1,530 articles from the selected appropriate electronic databases. Duplications (730 articles) were removed, and the remaining 800 articles were screened for inclusion in the integrative review. The majority of the articles (680 articles) focused on community-based projects and nursing students' experience with mentors in clinical placement areas. However, these were not relevant to the study and were eliminated as data. Of the remaining 120 fulltext articles only 38 met the inclusion criteria including five more in 2014 making the total number of articles reviewed to forty-three (see Figure 1).

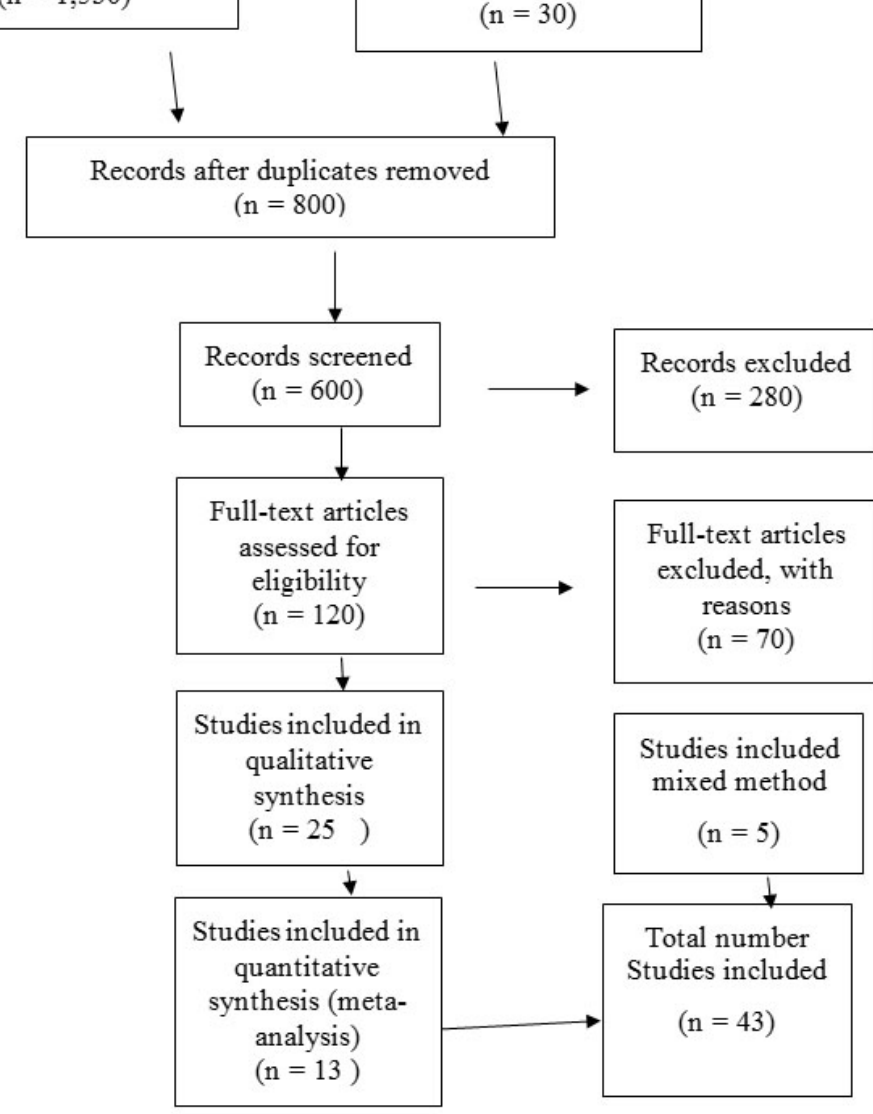

Figure 1. Flow chart of study selection process. Adapted from Moher D, Liberati A, Tetzlaff J, Altman DG, The PRISMA Group (2009). Preferred Reporting Items for Systematic Reviews and Meta-Analyses: The PRISMA Statement.

The review found that each study had suitable designs to establish quality appraisals. Using the Critical Appraisal Skills Program helped to focus the review on the rigour, methods, credibility, and relevance of the articles. This approach provided a final justification of the published articles for inclusion in the integrative review.

Published by Sciedu Press 
Of the 43 articles, 25 were qualitative research studies, 13 were quantitative research studies, and 5 mixed methods. Most of these employed cross-sectional surveys, qualitative interviews, and focus-group discussion methods with student and community stakeholders, and reflective journal diaries. These were consistent across the study methods.

\section{Discusion OF FINDINGS}

This integrative review of the literature sought to identify what was already known about community-based nursing education programs, its nature, and impact on nursing education. The studies used descriptive accounts in evaluating the development and implementation of the programs revealing five thematic categories: The nature and purpose of community nursing education; Significance of placement and learning environment; Impact of community nursing education; Challenges/barriers of community nursing education; and Nurse teacher/facilitator role.

These themes revealed students' learning activities, aiming to illustrate motivating work experiences in community areas while improving community well-being. ${ }^{[8,12-14]}$ The main settings included in the studies were the university, the community, and the primary schools which were involved in the community-based programs.

\section{Theme 1: The nature and purpose of community nurs- ing education}

Nursing education programs were planned curricula which involved both theory and practical experiences in clinical and community learning environments. The aim is to prepare future nurses to work in these settings. The current trend in healthcare focusing on community well-being has seen nursing education programs respond to the community-based approach of education and healthcare, integrating community components in the curriculum. ${ }^{[6,15]}$ The literature indicated that nursing education programs typically incorporate community placements in healthcare centres, schools and prisons. ${ }^{[12,16]}$

There is sufficient evidence to suggest that the nature and purpose of community nursing education provide the most influential learning experience of students to become competent health professionals as they bridge academic and workplace learning. ${ }^{[17]}$ However, there is a need for students to be supported as they learn to become competent professionals, otherwise demoralisation and alienation from the community may result. ${ }^{[18]}$

Furthermore, community nursing education as a pedagogical model ${ }^{[8]}$ enables students to learn to provide nursing care for people no matter where they are encountered. Mt- shali ${ }^{[6]}$ noted that community-based programs are mainly employed where universities are in partnership with the community. Buff et al. ${ }^{[19]}$ referred to these programs as 'community service-learning'-a reciprocal relationship between students and the community whereby both parties participate in service and learning. This approach goes beyond simple practice allocations and instead on a partnership between the university and the community, requiring that the needs of both parties are addressed in ways that the dignity and humanity of both parties are affirmed. For example, students' needs for learning are met through planned performance by providing services, thereby ensuring that community needs for services are met through student learning activities, e.g., through health promotion, early intervention, and illness prevention programs.

Poirrier ${ }^{[20]}$ viewed the nature of community nursing education as a strategy guiding nurse educators to prepare nurses for the 21 st century. This was important to healthcare, i.e., moving away from curative interventions to more preventive measures. ${ }^{[6]}$ Therefore, Zotti et al. ${ }^{[21]}$ suggested that attention to these programs rested on a community philosophy that guides care in all specialities and all settings that consist of more than observational experiences, as students engage in both service and learning. Mtshali ${ }^{[6]}$ acknowledged that the vital elements of this form of learning are reflective of the experience, and relationship reciprocities beneficial to students, their educational institutions, and the community. Therefore, the essential element of this educational approach is the collaboration between academic and community partners to define mutually meaningful learning for students. Most importantly, this pedagogical approach to education is a low-cost approach to achieving community well-being. ${ }^{[22]}$

The collaborative efforts of all stakeholders dispel the traditional idea that academic institutions are the 'ivory towers' of knowledge. Hence, the faculty and community are regarded as teachers and learners simultaneously. This process further empowers the community to have control over their lives. ${ }^{[23]}$ Nevertheless, this will only happen if collaborating partners in the projects are willing to explore their own social location, cultural values, and their relative privileges to understand how these influence the knowledge and experience generated in the project.

\section{Theme 2: Significance of placement learning environ- ment}

Several studies ${ }^{[24-28]}$ demonstrated the centrality of students' placement of learning environments. Placement experience shapes students' experience of the nursing program as a whole ${ }^{[29,30]}$ and provides socialisation to professional roles $^{[25,29]}$ and the development of students' professional 
identity. ${ }^{[29,31]}$ In their practice placements, students acquire nursing judgement, skills and knowledge ${ }^{[32]}$ and nursing professional values. Many studies ${ }^{[6,33-36]}$ found that placements of learning environments provide valuable experiences for both students and the community. Chan ${ }^{[37]}$ found that the environment had a direct impact on students' learning outcomes and provision of opportunities to combine cognitive, psychomotor, affective skills, and problem-solving abilities. She concluded that students' interpersonal relationships with healthcare professionals and autonomous learning within established student roles were crucial to positive learning environments. Community-based education placements are clearly relevant to the education of nursing students. ${ }^{[31,34,38]}$ They enhance student experiential learning ${ }^{[6,8,39]}$ and practicing simultaneously is widely regarded as a valuable tool for facilitating nursing students competencies for community practice. ${ }^{[29,34,36]}$ Students link theory to practice ${ }^{[6,34,40]}$ and through active participation, ${ }^{[41]}$ students acquire cultural competence. ${ }^{[6,42]}$ Community placements provide benefits to the community and educational institutions ${ }^{[36]}$ thus improving relationships. Experiential learning involves students putting theory into practice with resultant new knowledge capturing social reality. ${ }^{[6]}$ Morris $^{[43]}$ argues that learners should be guided to understand learning as 'how to do the job' by 'doing the job' (p. 48). Edwards et al. ${ }^{[29]}$ and Courtney et al. ${ }^{[44]}$ noted that it is in rural community settings that students capture some of the most critical competencies as they discover the ability to provide care to diverse populations. Edwards et al. ${ }^{[29]}$ found that rural students reported greater competence, confidence and organisational skills than did metropolitan students.

\section{Theme 3: The impact of community nursing education programs}

The theme revealed positive outcomes based on several factors, including collaborative partnership, impact to student learning, ${ }^{[12,36,45-50]}$ community academic partnership, ${ }^{[51,52]}$ cultural competence, ${ }^{[6,41,42]}$ faculty-student relationship ${ }^{[20]}$ and access to funding and developing a relationship between the university and community. ${ }^{[6,8,36,53]}$

Linda et $a .^{[8]}$ used an interpretive existentialistphenomenological approach to describe a community-based education program. The study found benefits to the community, including: developing partnership, increased awareness of services and sharing of resources. However, the study concluded that there was a need to improve communication between partners to enhance sustainability through closer interactive relationships. Also, some methodological challenges and ethical issues regarding child participants were raised.

Published by Sciedu Press
In their study of community-based education and service model at Makerere University, in Uganda, Mbalinda et al. ${ }^{[52]}$ found positive community outcomes, including decreased morbidity rates, increased health seeking behaviour and sustainable healthcare programs. However, sustainability and the lack of funding remained an issue, with community leaders declaring poor motivation due to a lack of compensation and fatigue.

Similarly, Luque \& Castañeda, ${ }^{[54]}$ in their study of a review of a practice model for community-academic partnership, found the model significant to the health of immigrants. They reaffirmed that for active partnership the need for such coalition must be continually re-energised. However, the literature also highlighted barriers to successful community-academic partnership experiences. Wolff \& Maurana ${ }^{[33]}$ suggested that mutual trust and respect are crucial elements that academics should tap into community knowledge and experience rather than taking it for granted. They recommended that for community-academic partnership to flourish, the institutions should avoid repeating previously failed partnerships by creating and nurturing trusting relationships. Arguably, academic institutions should strengthen trust-building as the hub of partnerships. Furthermore, Wolff \& Maurana ${ }^{[53]}$ caution that the process may not always be smooth and that it requires patience, sincerity, openness and willingness to work together.

Furthermore, a positive impact was revealed on student learning. For instance, in Uganda these programs were adapted to enhance students' learning in the community with the aim of enhancing interest of students working in rural areas of Uganda. ${ }^{[12,48-50]}$ Students indicated the possibility of taking their career into the community after graduation. However, being willing to work in rural communities and to achieve this goal are two different things in Uganda, wherein the infrastructure and funding for rural community work continue to be developed.

Kaye et al. ${ }^{[12]}$ found that training institutions had communitybased education attached to either primary healthcare practicum sites where medical and nursing students were linked to the community-where they could have hands-on experiences. They found that program sites offered multidisciplinary education, while others offered specific courses (for laboratory technicians). However, their evaluation study failed to capture the participant's voices and some were not specifically about nursing. Despite these shortfalls, the study does inform nurse educators about the implementation and organisation of community education programs. The major difficulties were related to funding and provision of appropriate mentors for the students. In addition, Kaye et al. ${ }^{[50]}$ 
identified multifactorial challenges; they found that there was no training for tutors of the program. The study concluded that the program needed further work and greater involvement of stakeholders, including the Ugandan government.

Mwanika et al. ${ }^{[49]}$ studied the evaluations of Makerere alumni of the community-based education program to which they had been exposed as students. A mixed method approach found that the program had positive impacts on the alumni. The alumni reported that the program had contributed to their confidence as health workers, communication skills and that as a result were willing to work in rural areas. However, it should be recognised that the sample size $(\mathrm{N}=7)$ of nursing students was small.

Chang et al. ${ }^{[48]}$ studied a community-based education program in Uganda assessed through student and educator perceptions using an internet based survey. The study found that all participants perceived the program positively and valued their experiences. They highlighted the need to address the lack of human and financial resources. However, the response rate (90 out of 300 alumni) was relatively low.

Studies Lynch et al. ${ }^{[47]}$ found that there was a positive impact on students' involvement in community-based education programs in the UK, particularly in relation to rural practice preparation. The findings indicated that community exposure successfully prepared the students for their subsequent clinical career. The literature also found that the impact of community nursing education led to community academic partnerships involving people from communities in analysing, decision-making, planning, evaluating and program implementation, ${ }^{[52]}$ including activities promoting achievements of sustainable development. Involving the community in shared goals and responsibilities, was shown to transform communities. ${ }^{[8,52]}$ Hunt \& Swiggum ${ }^{[51]}$ found that community members felt responsible for their health and wellbeing, while students and faculty gained knowledge and skills.

It is clear that students and faculty benefit from providing care in the community as traditional nursing boundaries are expanded in becoming teachers and learners simultaneously. The academic faculty are no longer the only source of knowledge, rather collaboration is seen as emerging through new partnerships between educational institutions and the community. ${ }^{[8,52,55]}$

Through community-partnership, students gain cultural competency. ${ }^{[6,41,42]}$ Amerson ${ }^{[42]}$ emphasised that acquisition of cultural competence needs constant, evolving level of knowledge and skills to work with diverse populations. CampinhaBacote $^{[56]}$ describes cultural competence constructs: "awareness, knowledge, skill, encounters, and desire” (p. 181).
Amerson ${ }^{[42]}$ suggests that students' exposure to culture and community enhances their understanding of the role culture plays in both education and practice. Similarly, Schuessler et al. ${ }^{[41]}$ acknowledges that cultural competence is acquired by students continuously.

Moreover, Schuessler et al. ${ }^{[41]}$ found that 'cultural humility' is first seen in the "first semester as students practice thinking and self-reflection in their journals" (p. 99) and start to recognise the importance of culture. It was found that the process was life-long and was still developing at the end of the course of study. The study found that students appreciated the similarities and dissimilarities among individual human beings and the impact on their care. Students came to understand that the best care was offered through respectful partnership with patients concluding that cultural humility requires reflection on experiences over time and that it cannot be learned in the classroom using traditional approaches.

An important outcome is the development of an enhanced faculty-student relationship which was highlighted in a study by Poirrier. ${ }^{[20]}$ The study found that community placements often resulted in students working closely with faculty in practice situations leading to enhanced relationships. Also, students who experienced being co-learners with their teachers considered it an important process; helping them to mature and feel adequate in practice. As they explored the unknown, their self-confidence began to deepen. Students' relationship with the community is enhanced as they begin to perceive themselves as competent providers of care.

\section{Theme 4: Challenges/barriers and sustainability of com- munity nursing education}

Edwards et al. ${ }^{[29]}$ found that rural placements required support structures to be in place. They suggested that students should have prior preparation and placement in the community needed to be planned carefully. Such preparation could help students, especially those without experience of rural life, to make the most of their placement opportunity. The evaluation of community programs ${ }^{[6,13,36]}$ revealed a number of challenges which had similarities regardless of geographical location, participants, and political, socio-cultural and economic status.

Significant challenges were associated with lack of resources, funding, and the lack of time. Community-based programs come with additional costs of travel and the need for educational materials. ${ }^{[36]}$ Funding issues exist both in developed and developing countries. Naidu et al. ${ }^{[36]}$ found that there was a need for supervisors with higher levels of competency to provide adequate support for students' learning needs in the community. The importance of this was realised in the 
study by Lynch et al. ${ }^{[46]}$ in which students attached their positive outcome of the program to the availability of suitably trained supervisors.

Lack of planning was noted in several studies ${ }^{[6,29]}$ leading to dissatisfaction among stakeholders. Mtshali ${ }^{[6]}$ found that limited pre-planning had a deleterious effect on the collaboration between stakeholders. Edwards et al. ${ }^{[29]}$ declared that adequate prior planning in fostering community alliances can contribute to a deeper understanding of the efforts needed to sustain effective relationships with the community. ${ }^{[8]}$

The challenge of cognitive 'untidiness' was highlighted in Carr's ${ }^{[39]}$ study finding that in the community, much of the power rests with clients because they are in their homes lifestyles varied and clients' problems failed to fit into neat categories. Carr ${ }^{[39]}$ observed that, "part of the community nurses' skills appeared to function within these apparently blurred boundaries and redefine the role as situations arose" (p. 334). It can be argued that the community clients' needs are not defined by medical diagnoses and as such the nurses' roles are correspondingly broad. Moreover, some students reported difficulty identifying clients' care needs. Students saw community practice as less standardised, less pre-determined, more negotiable and more open than hospital-based care. Although this presented students with conceptual difficulties, the students were at the same time able to see that individualised care was easier to achieve.

Community-based practice exposed the students to a great deal of information that is usually filtered out in the hospital environment. The result was that students identified and negotiated varied roles, managed different types of nursepatient relationships, undertook new types of assessment and participated in unfamiliar decision-making processes.

Baglin and Rugg ${ }^{[34]}$ noted that the lack of community practice experience created challenges to students learning in community settings. Students should be offered opportunity to practise skills in the community and to receive regular honest feedback from experienced nursing faculty. Most importantly, these opportunities should include exposure to real models of community action for health. ${ }^{[6]}$ While there are challenges in providing students with community experience, clearly such experience is valuable as learning-by-doing was an essential element in community placement allowing challenges to be addressed and critical thinking to advance. ${ }^{[38]}$

Sustainability is the continuity of the program's activities beyond the life of the initial funding. ${ }^{[8]}$ Wolff \& Maurana ${ }^{[53]}$ found that the partnership strengthened the community's capacity to gain skills and become involved in solving their problem. Partnership encouraged the community to work

Published by Sciedu Press towards sustainability of programs. They argued that for sustainability and ownership of the programs to take place, its consideration should start at the very beginning of the project and be achieved through attaining reciprocal relationships with the community.

Community members need to be involved and invested in, in order to assume community ownership. Failure to sustain some community health programs can lead to serious problems. Furthermore, they found that discontinuation of programs may negatively affect new programs as these may meet unexpectedly-reduced community support and trust. ShediacRizkallah \& Bone ${ }^{[57]}$ stressed that the literature identified funders and policy makers becoming increasingly concerned regarding sustainability of programs as they allocate scarce resources to community health programs.

\section{Theme 5: Nurse educator/facilitator role}

The importance of nurse educator/facilitator's role in teaching and guiding learners in the placement of learning environments is recommended, however, the university teachers were not actively involved in guiding students. ${ }^{[13]}$ The presence of educator's may colour the learning experiences of the students and avert challenges that students commonly face in this new learning environment. In addition, continuous feedback from academics 'on the ground' enables the desired outcomes to be achieved.

Community-based education calls for nurse educators to give up their old habits, philosophies and rationale for what nursing is and does. Similar findings were echoed in an empirical study by Saarikoski et al. ${ }^{[58]}$ on the role of nurse teacher in clinical practice. The quality of teachers' relationship with students was found to promote active learning in the practice area. Nurse educators are called upon to shift their focus towards the type of education that nursing students need in order to become successful learners in today's practice settings. ${ }^{[6]}$ However, preparation, guidance and support should also be offered to lecturers who are interested in learning community health concepts and developing collaborative skills with the community. By so doing the faculty, can be energised to embrace and move into this contemporary educational settings and enhance students' learning.

The curriculum should place emphasis on the shared responsibility between lecturers and mentors. ${ }^{[6]}$ Finnerty \& Pope ${ }^{[59]}$ found that the transfer of practical knowledge in professional practice "occurs through a range of subtle, often hidden, methods" (p. 315) and experience plays an important role. Consequently, student nurses develop both individual and professional maturity and become aware of the effect of their behaviour on themselves, their colleagues and their clients. 


\subsection{Methodological concerns and limitations of re-} viewed literature

Although the literature revealed a preponderance of data on the process of designing and implementing service learning programs, there was a lack of clarity concerning the variables that constituted an authentic partnership between an educational institution and the community. There was lack of thorough or systematic process of evaluating clients' responses to service learning activities. Evaluations of programs were carried out by internal rather than external evaluators. Most of the studies were conducted by researchers who were educators or practitioners; this could have influenced the objectivity of the studies. In many cases, the faculty members who created the programs were the authors and they seemed to be nested professionally and emotionally in program outcomes. In view of the above, a methodological observations approach could have reduced observer bias and led to strengthening the validity of conclusions about the programs' value to student learning and community problemsolving behaviours.

\subsubsection{Research methods}

Some studies failed to describe either the measurement instrument, such as survey or group discussion. Low response rates in interdisciplinary studies indicated how generalisability was limited. In some cases it was difficult to justify the authors' claims that both quantitative and qualitative methods were used in the studies reported. There were problems of methodological rigour, mainly because the results obtained by different research methods, and sources were not triangulated in the majority of the papers. In studies that used multiple data sources, only a few triangulated between methods and sources. ${ }^{[44,50]}$ Data collection varied from single to multiple techniques. Qualitative approaches mainly employed observations, interviews and open-ended survey questions while quantitative survey methods employed students' evaluations of learning and community benefits.

\subsubsection{Theoretical frameworks}

Most of the studies did not allude to theoretical frameworks for the design of the study or interpretation of findings. Few studies employed theoretical frameworks, while some studies did use theoretical frameworks, although none employed an African philosophy in guiding either the project being studied or the study itself. Arguably, there is a place for a wholly African concept, such as Ubuntu in such studies. Ubuntu is an African philosophical approach. Ubuntu is a fundamental predisposition by which people express and extend humanness within a community. ${ }^{[60]}$ Ubuntu promotes collaboration and working together and focusses on active participation and involvement of community members in community programs.

\subsubsection{Sampling procedure}

Sampling employed either purposive or convenience methods. The purposive sampling may have excluded sites where experiences were considerably different. Furthermore, recruitment of research participants was not apparent in some studies especially when only one participant from each site represented the community, as in the case of key informants.

\subsubsection{Process of securing informed consent}

In most of the studies this was not clearly described. Studies tended not to identify the process for gaining consent from students to analyse their journal entries or publish individual quotes instead of as an aggregate. Nursing scholars should pay attention to the ethics of research and clearly state the action taken to protect the participants. The choice of closed questioning (as in 'yes' or 'no') could have left many unanswered questions. There appeared to be some weakness in probing during the in-depth interviews, where researchers failed to find out what participants meant by what they were saying.

\subsubsection{Implications of the study}

This integrative review revealed limited publications on community nursing educational programs, such as in sub-Saharan Africa. Existing published studies showed that there are voices that need to be heard. Giving equal opportunities to publish can capture a comprehensive picture of community nursing education. Knowing experiences of stakeholders such as students, teachers, and the community would clearly inform similar programs involving community partnerships in preparation of nurses' responsiveness to the health and well-being of the community.

Nursing Education: Nursing education should promote new approaches using culturally appropriate models that take into consideration socio-political, cultural, socio-political economic and environmental aspects. There is a need for flexibility and adaptability in relation to program development so that it fits the purpose and is compliant with social and cultural needs and mandates. Furthermore, nurse educators should be prepared and trained in community mentorship. Given that the approach is quite different from mentorship in acute-care settings of the hospital, there should be necessary support for programs such as these. Challenges impeding student learning such as language barriers should be addressed and interventions developed to meet these challenges.

Nursing Practice: In having a community-based practice experience, future graduates can influence the community to enhance health promotive practices thus decreasing health problems and chronic illnesses resulting from poor health promotion practices. Therefore, given the increased health status of the community, there can be an expectation of less 
need for hospitalization thus influencing healthcare economic issues and concerns.

Nursing Policy: The integrative review revealed that community-based programs have the potential to reach the vulnerable and the underserved population through collaborative efforts that as individual healthcare practitioners may be unable to provide due to lack of resources. Through health promotion and illness prevention the community-based programs through limited community resources can affect and change the healthy lifeways of people and interact with others significantly. In this way, the community contributes to furthering community well-being while enhancing student learning. However, the success of these innovative programs depend on opportunities-funding for its sustainability is imperative. These programs should be positioned to receive adequate financial support from the government and the educational partners in order to meet the intended healthcare goals. Furthermore, from a pedagogical view, nurse educators need to incorporate community-based educational discussions into the curriculum and design policy statements to guide its implementation.

Nursing Research: This integrative review has found limited information on community nursing educational programs, especially in resource-poor settings as in sub-Saharan Africa. There are voices that need to be heard. By giving equal opportunity to all stakeholders, it is critical that further research can include the contributions of community-based nursing through the stakeholders' views. Capturing a comprehensive picture of community health is critical to the furtherance of human healthcare.

\section{Conclusion}

The integrative review focused on the nature, significance, barriers, impact, and appreciation of nurse educators regarding the pedagogies of community nursing education. Five themes were revealed, the nature and purpose of community-based nursing education, significance of placement and learning environment, the impact of communitybased nursing education, the challenges and sustainability of community-based nursing education programs, and nurse educator/facilitator role.

While the innovative pedagogical approaches showed positive impacts enhancing students' learning as well as community health, there is a great need to address the pedagogical barriers and challenges in order to achieve outcomes and sustainability. Voices of all stakeholders need to be heard. The study found relatively few studies undertaken in resourcepoor settings, while most studies were from USA, UK, Australia, and South Africa. This review recognized the need for further research in order to provide credible evidence of the educational, political, research, and practice usefulness of this new pedagogical approach to nursing education.

\section{ACKNOWLEDgements}

Supervisor Dr. Jeremy J. Jolley for his enormous support, encouragement and guidance in conducting the search for literature.

\section{CONFLicts OF INTEREST Disclosure}

The authors declare that there is no conflict of interest.

\section{REFERENCES}

[1] Kristina TN, Majoor GD, Van Der Vleuten CPM. Defining generic objectives for community-based education in undergraduate medical programs. Medical Education. 2004; 38(5): 510521. PMid:15107085 http://dx.doi.org/10.1046/j.1365-2 929.2004.01819.x

[2] Mullan F, Epstein L. Community-oriented primary care: new relevance in a changing world. American Journal of Public Health. 2002; 92 (11): 1748-1755. PMid:12406800 http://dx .doi.org/10.21 05/AJPH. 92.11 .1748

[3] Diekelmann N. Narrative pedagogy: Heideggerian hermeneutical analyses of lived experiences of students, teachers and clinicians. Advances in Nursing Science. 2001; 23: 53-71. PMid:11225050 http: //dx.doi.org/10.1097/00012272-200103000-00006

[4] World Health Organisation. Community-Based Education of Health Personnel: WHO Study Group Report. Geneva, WHO. 1987; 746: 1-89.

[5] Salmon K, Keneni G. Student nurses' learning on community-based education in Ethiopia. Education Health (Abingdon). 2004; 17(2):
172-182. PMid:15763760 http://dx.doi.org/10.1080/13576 280410001710996

[6] Mtshali NG. Implementing community-based education in basic nursing education programs in South Africa. Curationis. 2009; 32(1): 25 32. http://dx.doi.org/10.4102/curationis.v32i1.870

[7] Oermann MH, Heinrich KT. Annual review of nursing education. New York, Springer Publishing Company; 2003

[8] Linda NSB, Mtshali NG, Engelbrecht C. Lived experiences of a community regarding its involvement in a university community-based education program. Curationis. 2013; 36(1): 1-13. PMid:23718158 http://dx.doi.org/10.4102/curationis.v36i1.78

[9] Burns N, Groves SK. Understanding nursing research: building an evidence based practice. New York, Elsevier; 2010.

[10] CASP UK. Critical Skills Appraisal Program. 2014.

[11] Moher D, Liberati A, Tetzlaff J, et al. The PRISMA Group. Preferred Reporting Items for Systematic Reviews and Meta-Analyses: The PRISMA Statement. PLoS Med. 2009; 6(7): e1000097. PMid:19621072 http://dx.doi.org/10.1371/journal.pmed. 1000097 
[12] Kaye D, Mwanika A, Burnham G, et al. The organization and implementation of community-based education programs for health worker training institutions in Uganda. International Health and $\mathrm{Hu}-$ man Rights. 2010a; 11(Sup-1): S1-S4.

[13] Mabuza LH, Diab P, Reid SJ, et al. Communities' views, attitudes and recommendations on community-based education of undergraduate health sciences students in South Africa. African Journal Primary Health Care Family Medicine. 2013; 5(1): 456-459. http://dx.doi.org/10.4102/phcfm.v5i1.456

[14] Mtshali NG. Conceptualisation of community- based basic nursing education in South Africa: a grounded theory analysis. Curationis. 2005; 28(2): 5-12. http://dx.doi.org/10.4102/curationis . v28i2. 939

[15] Reimer Kirkham S, Hoe Harwood C, Terblanche L, et al. The use of innovative clinical placements: A national survey. Final Report. 2007 Unpublished Manuscript. Trinity Western University Langley, B.C.

[16] Frank B, Adams MH, Edelstein J, et al. Community-based nursing education of prelicensure students: settings and supervision. Nursing Education Perspectives. 2005; 26(5): 283-286. PMid:16295307

[17] Rodger S, Fitzgerald C, Davila W, et al. What makes a quality occupational therapy practice placement? Students' and practice educators' perspectives. Australian Occupational Therapy Journal. 2011; 58(3): 195-202. PMid:21599685 http://dx.doi.org/10.1111/j.144 $0-1630.2010 .00903 . \mathrm{x}$

[18] Bradbury-Jones C, Sambrook S, Irvine F. Empowerment and being valued: A phenomenological study of nursing students' experiences of clinical practice. Nurse Education Today. 2011; 31(4): 368-372. PMid:20696505 http://dx.doi.org/10.1016/j.ned t. 2010.07 .008

[19] Buff SM, Jenkins K, Kern D, et al. Interprofessional service-learning in a community setting: findings from a pilot study. Journal of Interprofessional Care. 2014; 8: 1-3.

[20] Poirrier G. Service learning: Curricular applications in nursing. 2001 Boston, Jones and Bartlett.

[21] Zotti ME, Brown P, Stotts R. Community-based nursing versus community health nursing: what does it all mean? Nursing Outlook. 1996; 44(5): 211-217. http://dx.doi.org/10.1016/S0029-6 554 (96) 80094-7

[22] Beauchesne MA, Meservey PM. An interdisciplinary communitybased educational model. Journal of Professional Nursing. 1999; 15(1): 38-43. http://dx.doi.org/10.1016/S8755-7223(99 ) $80024-6$

[23] Carter KF, Fournier M, Grover S, et al. Innovations in communitybased nursing education: transitioning faculty. Journal of Professional Nursing. 2005; 21(3): 167-174. http://dx.doi.org/10.1016/j .profnurs.2005.04.004

[24] Baillie L. Factors affecting student nurses' learning in the community placements: A phenomenological study. Journal Advanced Nursing 1993; 18(7): 1043-1053. http://dx.doi.org/10.1046/j.136 5-2648.1993.18071043.x

[25] Papp I, Markkanen M, von Bonsdorff M. Clinical environment as a learning environment: student nurses' perceptions concerning clinical learning experiences. Nurse Education Today. 2003; 23(4): 262-268. http://dx.doi .org/10.1016/S0260-6917(02)00185-5

[26] Chesser-Smyth PA. The lived experiences of general student nurses on their first clinical placement: a phenomenological study. Nurse Education in Practice. 2005; 5(6): 320-327. PMid:19040840 http: //dx.doi.org/10.1016/j.nepr.2005.04.001

[27] Papastavrou E, Lambrinou E, Tsangari H, et al. Student nurses experience of learning in the clinical environment. Nurse Education in Practice. 2010; 10(3): 176-182. PMid:19700368 http: //dx.doi.org/10.1016/j.nepr.2009.07.003
[28] Courtney-Pratt H, FitzGerald M, Ford K, et al. Quality clinical placements for undergraduate nursing students: a cross-sectional survey of undergraduates and supervising nurses. Journal of Advanced Nursing. 2012; 68(6): 1380-90. PMid:22043859 http: //dx.doi.org/10.1111/j.1365-2648.2011.05851.x

[29] Edwards H, Smith S, Courtney M, et al. The impact of clinical placement location on nursing students' competence and preparedness for practice. Nurse Education Today. 2004; 24(4): 248 255. PMid:15110433 http://dx.doi.org/10.1016/j.nedt. 20 04.01 .003

[30] Pearcey P, Draper P. Exploring clinical nursing experiences: listening to student nurses. Nurse Education Today. 2008; 28: 595 560. PMid:17950499 http://dx.doi.org/10.1016/j.nedt. 20 07.09 .007

[31] Dornan T, Bundy C. What can experience add to early medical education? Consensus survey. British Medical Journal. 2004; 329(7470): 834. PMid:15472265 http://dx.doi.org/10.1136/bmj . 329.7 470.834

[32] Hartigan-Rogers J, Corbbett SL, Amirault MA, et al. Nursing graduates perceptions of their undergraduate clinical placement. International Journal of Nursing Education Scholarship. 2007; 4(1): 1-12. PMid:17402935 http://dx.doi.org/10.2202/1548-923X.12 76

[33] Lea J, Cruickshank M, Paliadelis P, et al. The lure of the bush: do rural placements influence student nurses to seek employment in rural settings? Journal of Collegian. 2008; 15(2): 77-82. http: //dx.doi.org/10.1016/j.colegn.2008.02.004

[34] Baglin MR, Rugg S. Student nurses' experiences of communitybased practice placement learning: a qualitative exploration. Nurse Education in Practice. 2010; 10(3): 144-152. PMid:19570716 http: //dx.doi.org/10.1016/j.nepr.2009.05.008

[35] Marshall P, Shelton R. Preparing nursing students to be community health practitioners. British Journal of Community Nursing. 2012; 17(12): 622-629. http://dx.doi.org/10.12968/bjcn.2 012.17 .12 .622

[36] Naidu CS, Zweigenthal V, Irlam J, et al. An evaluation of University of Cape Town medical students' community placements in South Africa. African Journal Primary Health Care Family Medicine. 2012; 4(1): 448-455. http://dx.doi.org/10.4102/phcfm.v4i1. 44 8

[37] Chan DS. The relationship between student learning outcomes from their clinical placement and their perceptions of the social climate of the clinical learning environment. Contemporary Nurse. 2004; 17(1-2): 149-58. PMid:17929746 http://dx.doi.org/10.5172 /conu.17.1-2.149

[38] Stockhausen LJ. Learning to become a nurse: student nurses' reflections on their clinical experiences. Australian Journal of Nursing. 2005; 22(3): 8-14.

[39] Carr S. Nursing in the community: Impact of context on the practice agenda. Journal of Clinical Nursing. 2001; 10(3): 330-336. http://dx.doi.org/10.1046/j.1365-2702.2001.00466.x

[40] Mabuda BT, Potgieter E, Alberts UU. Student nurses' experiences during clinical practice in the Limpopo Province. Curationis. 2008; 31(1): 19-27. http://dx.doi.org/10.4102/curationis.v3 1 i 1.901

[41] Schuessler JB, Wilder B, Byrd LW. Reflective journaling and development of cultural humility in students. Nursing Education Perspectives. 2012; 33(2): 96-99. http://dx.doi.org/10.5480/1 536-5026-33.2.96

[42] Amerson R. The impact of service-learning on cultural competence. Nursing Education Perspectives. 2010; 31(1): 18. PMid:20397475 
[43] Morris C. Facilitating learning in the workplace. British Journal of Hospital Medicine. 2010; 71(1): 48-50. PMid:20081643 http: //dx.doi.org/10.12968/hmed.2010.71.1.45974

[44] Courtney M, Edwards H, Smith S, et al. The impact of rural clinical placement on student nurses' employment intentions. Collegian. 2002; 9(1): 13-18. http://dx.doi.org/10.1016/S1322-769 6(08) 60039-6

[45] Kenyon L, Peckover S. A Juggling Act: an analysis of the impact of providing clinical placements for pre- registration students on the organisation of community nursing and health visiting work. Nurse Education Today. 2008; 28(2): 202-209. PMid:17512096 http://dx.doi.org/10.1016/j.nedt.2007.03.014

[46] Playford D, Wheatland B, Larson A. Does teaching an entire nursing degree rurally have more workforce impact than rural placements? Contemporary Nurse. 2010; 35(1): 68-76. PMid:20636179 http://dx.doi.org/10.5172/conu.2010.35.1.068

[47] Lynch CD, Ash PJ, Chadwick BL, et al. Evaluation of a U.K. community-based clinical teaching/outreach program by former dental students two and five years after graduation. Journal of Dental Education. 2010; 74(10): 1146-1152. PMid:20930246

[48] Chang LW, Kaye D, Muhwezi WW, et al. Perceptions and valuation of a community-based education and service (COBES) program in Uganda. Medical Teacher. 2011; 33(1): 9-15. PMid:21182375 http://dx.doi.org/10.3109/0142159x.2011.530317

[49] Mwanika A, Okullo I, Kaye DK, et al. Perception and valuations of community-based education and service by alumni at Makerere University College of Health Sciences. International Health and Human Rights. 2011; 11(Sup 1): S1-S5.

[50] Kaye DK, Muhwezi WW, Kasozi AN, et al. Lessons learnt from comprehensive evaluation of community-based education in Uganda: a proposal for an ideal model community-based education for health professional training institutions. Medical Education. 2011b; 11: 7. http://dx.doi.org/10.1186/1472-6920-11-7

[51] Hunt R, Swiggum P. Being in another world: transcultural student experiences using service learning with families who are homeless. Journal of Transcultural Nursing. 2007; 18(2): 167-174. PMid:17416719 http://dx.doi.org/10.1177/1043659606298614
[52] Mbalinda SN, Plover CM, Burnham G, et al. Assessing community perspectives of the community based education and service model at Makerere University, Uganda: a qualitative evaluation. International Health and Human Rights. 2011; 11(Sup. 1): S1-S6.

[53] Wolff M, Maurana CA. Building effective community-academic partnerships to improve health: a qualitative study of perspectives from communities. Academic Medicine. 2001; 76(2): 166-172. PMid:11158838 http://dx.doi.org/10.1097/00001888-200 102000-00016

[54] Luque JS, Castañeda H. Delivery of mobile clinic services to migrant and seasonal farmworkers: a review of practice models for community-academic partnerships. Journal Community Health. 2013; 38(2): 397-407. PMid:23054421 http://dx.doi.org/10.1007 /s10900-012-9622-4

[55] Nehls N, Vandermause R. Community- driven nursing transforming nursing curricula and instruction. Nurse Education Perspective. 2004; 25(2): 81-5. PMid: 15124512

[56] Campinha-Bacote J. The process of cultural competence in delivery of Healthcare service: a model of care. Journal of Transcultural Nursing. 2002; 13(3): 181-184. http://dx.doi.org/10.1177/10459 602013003003

[57] Shediac-Rizkallah MC, Bone LR. Planning for the sustainability of community-based health programs: conceptual frameworks and future directions for research, practice and policy. Health Education Research. Theory and practice. 1998; 13(1): 87-108.

[58] Saarikoski M, Warne T, Kaila P, et al. The role of the nurse teacher in clinical practice: an empirical study of Finnish student nurse experiences. Nurse Education Today. 2009; 29(6): 595600. PMid:19232789 http://dx.doi . org/10.1016/j . nedt. 20 09.01 .005

[59] Finnerty G, Pope R. An exploration of student midwives' language to describe non-formal learning in professional practice. Nurse Education Today. 2005; 25(4): 309-315. PMid:15896416 http://dx.doi.org/10.1016/j.nedt.2005.02.001

[60] Nussbaum B. African culture and Ubuntu: reflections of a South African in America. World Business Academy. 2003; 17(1): 1-12. 